\title{
Combustion behaviors of hydrogenated and unhydrogenated colophony esters/petroleum resins using TG-FTIR and DFT
} analysis

\author{
Dan Zhou ${ }^{1}$, Xiaopeng Chen ${ }^{2}$, Jiezhen Liang ${ }^{1}$, Xiaojie $\mathrm{Wei}^{1}$, Chenghong $\mathrm{Wu}^{1}$, Yaoliang $\mathrm{He}^{1}$, \\ and Linlin Wang ${ }^{1}$
}

${ }^{1}$ Affiliation not available

${ }^{2}$ Guangxi University

September 24, 2021

\begin{abstract}
The combustion behavior of tackifying resins (such as glycerol ester of colophony/hydrogenated colophony and C9/hydrogenated C9 petroleum resin, namely GEC, GEHC, C9PR and HC9PR, respectively) were investigated using TG-FTIR and density functional theory (DFT) analyses. Results from combustion characteristics indicate tackifying resins and their wastes are a promising fuel for generating energy. The average activation energies obtained by Friedman method for GEC, GEHC, C9PR and HC9PR were 223.51, 162.16, 166.52 and $116.20 \mathrm{~kJ} / \mathrm{mol}$, respectively, revealing that $(\mathrm{H}) \mathrm{C} 9 \mathrm{PR}$ were more readily combustible than $\mathrm{GE}(\mathrm{H}) \mathrm{C}$, and their hydrogenated products burned more easily than their unhydrogenated ones, which were strongly supported by the TG-FTIR results. DFT calculations also show that the bond dissociation energy of C-C bond of GEC is higher than those of C9PR and GEHC. The best appropriate reaction mechanism evaluated by integral master plots is $\mathrm{f}(\alpha)=3(1-\alpha) 2 / 3$. Volatiles are mainly composed of $\mathrm{H} 2 \mathrm{O}, \mathrm{CH} 4, \mathrm{CO} 2, \mathrm{CO}$, alcohol, aromatic and carbonyl compounds.
\end{abstract}

\section{Hosted file}

manuscript.docx available at https://authorea.com/users/435035/articles/538337-combustionbehaviors-of-hydrogenated-and-unhydrogenated-colophony-esters-petroleum-resins-using-tgftir-and-dft-analysis 
Graphical Abstract

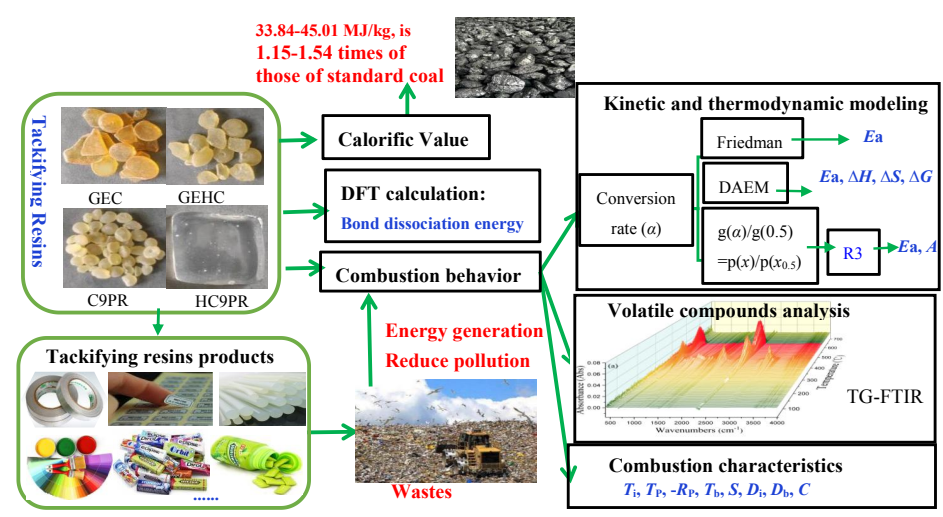

